Article

\title{
Highly Productive Synthesis of 1-Propenyloxybutan-1-ol Under Solvent-Free Homogeneous Ruthenium Catalyst Conditions
}

\author{
Magdalena Urbala \\ Faculty of Chemical Technology and Engineering, Department of Chemical Organic Technology and Polymeric \\ Materials, West Pomeranian University of Technology, 42 Piastów Avenue, 71-065 Szczecin, Poland; \\ mu@zut.edu.pl \\ Received: 10 November 2020; Accepted: 27 November 2020; Published: 2 December 2020

\begin{abstract}
The 1-propenyl ethers bearing free hydroxyl groups of $\mathrm{CH}_{3} \mathrm{CH}=\mathrm{CH}-\mathrm{O}-\mathrm{A}-\mathrm{OH}$ type (hydroxyalkyl 1-propenyl ethers, 1-propenyloxyalcohols) are the most desired as the reactive diluents for photopolymerizable systems with enhanced reactivity or intermediates for the synthesis of hybrid monomers for special applications. The ruthenium complexes-catalyzed isomerization of allyl ethers under solvent-free conditions is an atom-economical and environmentally sustainable method for their production. Here, the reaction conditions and limitations for the highly productive and selective synthesis of model 4-(1-propenyloxy)butan-1-ol have been investigated. The minimal loading of ruthenium pre-catalysts needed for completion of reaction within reasonable times was priority assumption. It was found that $\left[\mathrm{RuClH}(\mathrm{CO})\left(\mathrm{PPh}_{3}\right)_{3}\right]$ or $\left[\mathrm{RuCl}_{2}\left(\mathrm{PPh}_{3}\right)_{3}\right]$ exhibited extremely high catalytic activity under optimized non-oxidative reaction conditions. The key effect of reaction temperature on the activation pre-catalyst and the exothermal effects of isomerization was discovered. The practically quantitative yields of 4-(1-propenyloxy)butan-1-ol were achieved with using of very low loading of $[\mathrm{Ru}](5 \mathrm{ppm})$ and $\mathrm{Bu}_{3} \mathrm{~N}$ (to maintain reaction chemoselectivity) at the temperature of $120^{\circ} \mathrm{C}$ for only $0.5 \mathrm{~h}$. Consequently, the attained TON (turnover number) and TOF (turnover frequency) values of ca. 198,000 and 390,000 $\mathrm{h}^{-1}$ were unprecedentedly high and industrial attractive. On the other hand, the direct recycling of ruthenium catalyst is not a reasonable method for improving catalyst productivity.
\end{abstract}

Keywords: isomerization; double-bond migration; ruthenium complex; allyl ethers; 1-propenyl ethers; allyloxyalcohols; recycling of homogeneous catalyst; UV-cured monomers

\section{Introduction}

During the last 30 years, the use of homogeneous catalysis with soluble transition metal complexes (TMCs) for the fine chemical, chemical specialties, pharmaceutical and polymer production is rapidly expanding. Among TMCs, those from platinum group metals such as ruthenium, rhodium, palladium, osmium, iridium, and platinum are used extensively as catalysts. In many cases, they offer the unique possibility of fast and atom-efficient, high hemo-, regio-, and enantioselective and high-yielded synthesis of desired chemical molecules under mild and often solvent-less reaction conditions. These clean catalytic technologies play a key role in the drive towards environmentally benign processes with minimal waste generation (sustainable development, "green chemistry" concept) [1-3]. However, the important challenges in the field of technological usefulness of homogeneous catalysts are to develop sustainable processes with improved economic viability $[4,5]$.

The isomerization of alkenes and their derivatives catalysed by TMCs is well-recognised in academic and industrial organic chemistry [6-8]. It is an elegant, green, clean, $100 \%$ atom-economic, 
one-pot, and one-step, efficient and environmentally sustainable way to valuable products, often without producing any by-products and without requiring toxic reagents. Nowadays, among these reactions, the isomerisation of allyl systems is of high interest in fine chemistry [8]. The most spectacular processes of isomerization of allyl systems (alkenes, alcohols, ethers or amines), which can be realized on an industrial scale, among others:

- Isomerization of allyl alcohols towards appropriate ketones and aldehydes (e.g., methyl ethyl ketone MEK, butanal) [9],

- (E)-Stereoselective isomerization of functionalized allylbenzene-for the synthesis of some terpenes ("phenylpropenoids"), which are known as flavouring agents used in the food, cosmetic and pharmaceutical industries, for example the isomerization of methylchavicol to (E)-anethole [10],

- Enantioselective isomerisation of $N$-allyl systems-the key step of synthesis of (-)-menthol on the industrial scale, developed and implemented by Takasago Int. Co., as early as 1983 [11],

- Tandem ring-closing metathesis-isomerization reaction (RCM) leading to the synthesis of interesting carbo- and heterocyclic compounds [12],

- Tandem isomerization-Claisen rearrangement of bis(allyl) ethers (ICR)-the synthesis of functionalized aldehydes or ketones [13],

- Isomerization allyl ethers to 1-propenyl ethers-a key step of deprotection of the hydroxy groups protected by allyl groups in the of sugars and drugs chemistry [14], as well as a method for the preparation of UV-reactive 1-propenyl monomers [15].

The both fundamental and applied aspects of the isomerization of multi-functional alkyl allyl ethers to 1-propenyl derivatives catalyzed by ruthenium complexes [16-21], including the synthesis of high purified allyl substrates [22] and also the application of 1-propenyl ether monomers in the UV-curing polymeric systems [23-25] are the main focus of the research in our group (Scheme 1):

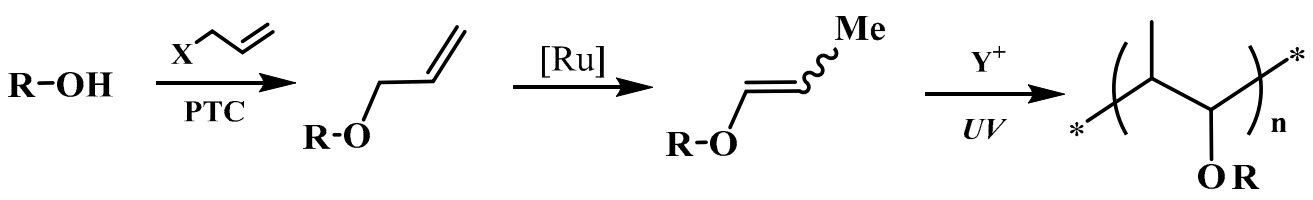

Scheme 1. The strategy of the synthesis and application of 1-propenyl monomers.

The majority of success of this strategy deal with the possibility using of a wide variety of alcohols, diols and polyols both bio-based and synthetic sources, ecological way of high pure allyl substrates synthesis under Phase Transfer Catalysis (PTC) conditions, the low-valent hydride ruthenium complexes as very effective and relatively cheap pre-catalyst of isomerization under mild reactions conditions and ensuring high selectivity and yield of main often multifunctional 1-propenyl products. Moreover, no doubt much of the interest arises from the potential commercial importance of the application of 1-propenyl ether as components (monomers, co-monomers, reactive diluents, modifying agents) of cationic photopolymerized heterocyclic systems (e.g., epoxides, oxetanes). The modern clean cationic photopolymerization technology is progressively implemented in various important industrial practice fields, for instance, microelectronics, optoelectronics, polygraphy, mainly in very fast thin polymeric film production, like coatings, lacquers, adhesives, inks, pigments, print inks applied to all kind of materials [26]. In practice, the 1-propenyl ether bearing free hydroxyl groups of $\mathrm{CH}_{3} \mathrm{CH}=\mathrm{CH}-\mathrm{O}-\mathrm{A}-\mathrm{OH}$ type (hydroxyalkyl 1-propenyl ethers, 1-propenyloxyalcohols) as the bifunctional monomers, so-called monofers [27] are the most attractive because they contain both polymerizable 1-propenyl groups and a hydroxy moiety that induce chain transfer (and, in consequence, accelerate polymerization of heterocyclic monomers [28]) or open pathways for the synthesis of large variety hybrid systems [29-31].

Unfortunately, so far apart from simple, practically useless for photopolymerization process, 1-propenyl ethers (e.g., methyl- and ethyl-(1-propenyl) ether), valuable O-1-propenyl monomers are not commercially available. It would relate to the fact that contrary to allyl alcohols, the isomerization of 
allyl ethers, particularly allyloxyalcohols, is not explored sufficiently both from basic and technological points of view, until now. The synthesis of 1-propenyloxyalcohols (even on preparative scale) was mostly realized with non-effective and ecologically undesired base catalytic systems such as $t$-BuOK (huge excess, moisture sensitive) in DMSO (very hygroscopic) (yields ca. $60-80 \%$ ) $[29,30]$ or heterogeneous catalyst such as $\mathrm{Pd} / \mathrm{C}$ (yields ca $40 \%$ ) [32].

Recently, we have first presented the possibility of using ruthenium complexes as an active and high selective catalyst for the isomerization of allyloxyalcohols toward 1-propenyl derivatives [19-21]. We demonstrated that the difficulty in the conducting of the allyloxyalcohols isomerization in the presence of TMCs complexes is the fact that this reaction could leads to 1-propenyl derivatives and also products of the intra- and/or intermolecular addition of an $\mathrm{OH}$ group to the double bond (Scheme 2). Moreover, we established that only the hydride mechanism of the double bond migration and also binding of the pure $\mathrm{HCl}$ formed in situ from chloride ligand and hydroxyl group [33] guarantee the formation 1-propenyl product solely [21]. So, besides $\left[\mathrm{RuClH}(\mathrm{CO})\left(\mathrm{PPh}_{3}\right)_{3}\right]$ (well-known and versatile pre-catalyst for isomerization alkenes [34], allyl alkyl ethers [16], allyloxyalcohols [19,20] and many others) we have discovered new efficient catalysts for the allyloxyalcohols isomerization, mainly $\left[\mathrm{RuH}_{2}(\mathrm{CO})\left(\mathrm{PPh}_{3}\right)_{3}\right]$ or $\left[\mathrm{RuCl}_{2}\left(\mathrm{PPh}_{3}\right)_{3}\right]+$ amine $\left(\mathrm{Et}_{3} \mathrm{~N}, \mathrm{Bu}_{3} \mathrm{~N}\right)$ [21]. On the other hand, the second reaction way toward acetals (cyclic or linear) is the attractive method of synthesis of unsymmetrical acetals, orthoesters and isoxazoles in tandem isomerization-addition or isomerization-dipolar cycloaddition reactions [35].

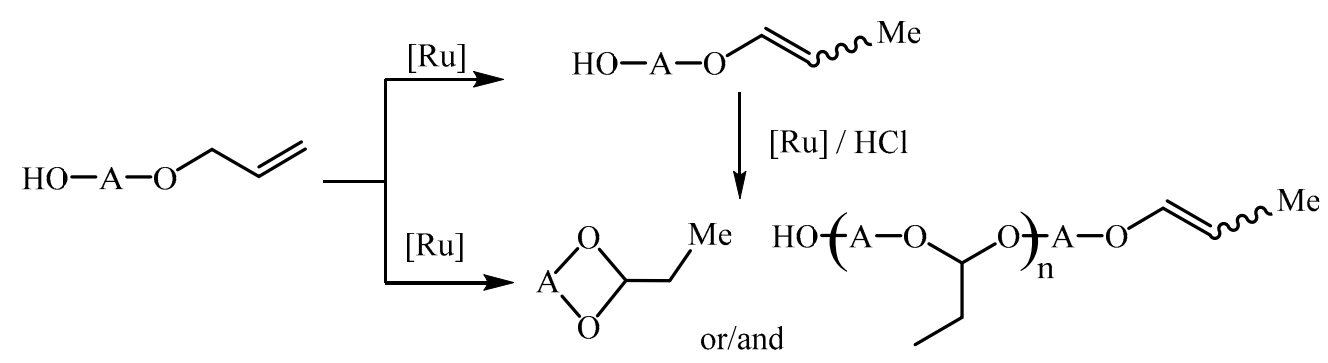

Scheme 2. The reaction ways of allyloxyalcohols with soluble ruthenium complexes.

However, it is well-known that the platinum metals (ruthenium) used as catalysts and also some organic ligands (especially chiral) are relatively expensive. So, a large part of the research is aimed at increasing the intrinsic rate of the reaction, often expressed as turnover frequency (TOF) and catalyst stability, expressed as turnover number (TON) (or total turnover number TTN in the case of the recycling of catalyst). It is clear from our previous results that the relatively high concentrations of [Ru] complexes $(0.02 \mathrm{~mol} \%, 0.05 \mathrm{~mol} \%$ or $0.1 \mathrm{~mol} \%)$ were necessary to ensure the completion of the reaction [21] and, as a consequence, unsatisfactory values of TON in the range of 1000 to 5000 were reached (Scheme 3).

Thus, further studies on increasing the productivity of the ruthenium catalytic systems in this type of the isomerization reaction were required. In order to obtain the highest values of TON, the substrates must be converted selectively into the desired product with quantitative yield in the presence of minimal loading of catalyst. In this context, there are some basic concepts related to practical homogeneous catalysis:

1. The screening of commercially available metals, ligands, counterions (for example by high-throughput experimentation method) and also the reaction conditions, such as solvents, temperature, pressure, order of addition, etc.

2. The improving of catalyst stability, for example by determination of potential sources of catalyst inhibition or deactivation such as substrate or product, inhibiting impurities of starting material/solvent, products of decompositions of labile ligands,

3. The recycling of catalyst in the bath mode systems (if the suitable method of catalysts separation from the product without loss of their stability is possible) [5]. 
According to the above and to the fact that the commercially available hydride triphenylphosphine ruthenium complexes were previously indicated as active catalysts (Scheme 3) [21], in this work, the solvent-free isomerization process of allyloxyalcohols toward 1-propenyloxyalcohols was optimized to achieve higher value of TON and TOF of ruthenium catalyst, sufficiently high to make this route economically successful. In the continuation of our study the commercially available model 4-allyloxybutan-1-ol and simple ruthenium complexes were chosen as allyl substrate and catalyst precursors. This time the emphasis was directed on the using of minimal concentration of ruthenium complexes, including the effect of allyl substrate impurities (allyl hydroperoxides, AHP), amine (to maintain reaction chemoselectivity)o 1-propenyloxyalcohol product) within the reasonable reaction times. Additionally, the effect of recycling of ruthenium catalyst on its productivity was conducted.

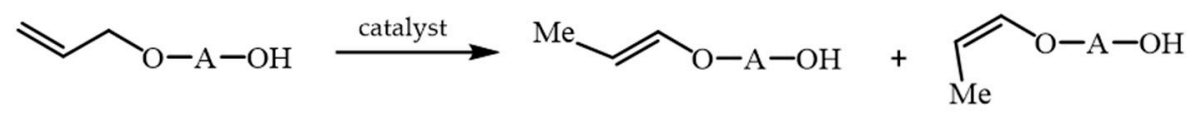

Previous works:

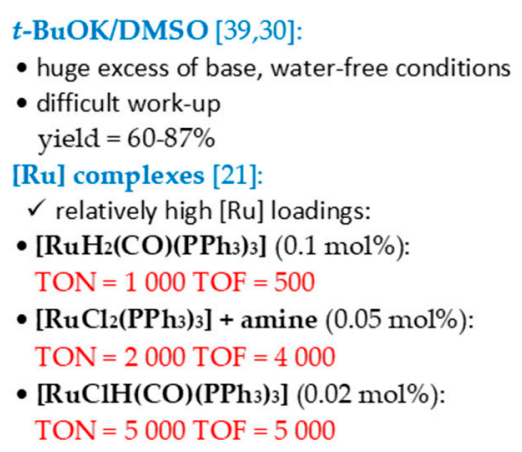

Scheme 3. Concept of high productive synthesis of 1-propenyloxyalcohols.

\section{Results and Discussion}

The isomerization reaction of model 4-allyloxybutan-1-ol with simple ruthenium complexes under solvent-free conditions runs solely toward the 1-propenyl ether isomers (a mixture of $\mathrm{Z}$ and $\mathrm{E}$ stereoisomers) i.e., (Z)- and (E)-4-(1-propenyloxy)butan-1-ol and/or cyclic acetal i.e., 2-ethyl-1,3-dioxepine (Scheme 4) [21].

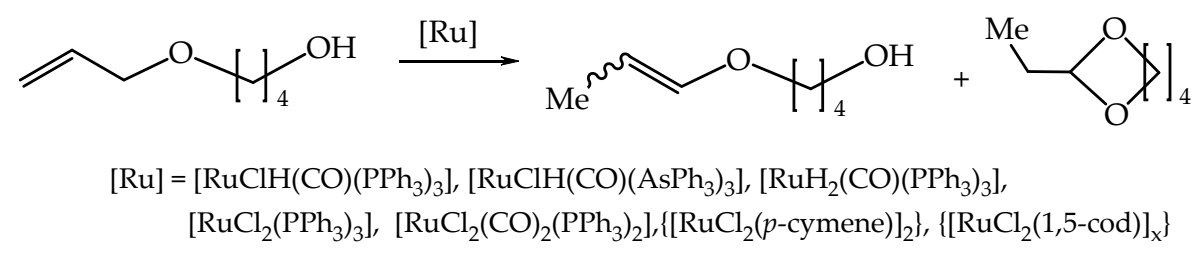

Scheme 4. The reaction of 4-allyloxybutan-1-ol with ruthenium complexes.

For the investigation of the technological usability of the 1-propenyloxyalcohols synthesis methods, developed by us, the effect of allyl hydroperoxides (AHP) on the catalytic activity of ruthenium catalysts was first explored.

Generally, it is well-known that the allyl hydroperoxides are easily formed via the autoxidation reaction of allyl ethers with the oxygen form air, which is utilized in UV-curing coating industry based on unsaturated polyester resins. The addition of allyl ethers to polyester resin prevents the inhibiting effect of oxygen on free-radical polymerization and makes modified resin curable in the air [36]. On the other hand, in the homogeneous catalysis with ruthenium complexes the presence of peroxides in the reaction system can sometimes cause problems by oxidizing organometallic catalysts and convert them into new complexes [37]. However, in the case of double-bond isomerization the traces of AHP 
can accelerate or inhibit the reaction rate. This behaviour strongly depends on the structure of [Ru] pre-catalyst and also the structure of unsaturated substrate. For example, in the case of the most popular $\left[\mathrm{RuCl}_{2}\left(\mathrm{PPh}_{3}\right)_{3}\right]$ and olefin or alkyl allyl ethers as substrates, the peroxides act as very active catalyst activators $[17,38]$, while in allyl glycidyl ether isomerization they significantly reduced reaction progress [18]. However, notwithstanding this, there is no doubt that AHP is one of the most important factors affecting the efficiency of $[\mathrm{Ru}]$ complexes. Moreover, from the technological point of view, it is highly desirable to determine the effectivity of [Ru] catalyst without further purification of allyl substrate. Additionally, in the allyloxyalcohol isomerization case, it was interested to examine whether the AHP can be able to enhance the chemoselectivity reaction towards 1-propenyl ethers.

For these purposes, first, we monitored the rate of autoxidation of pure substrate during its storage in amber bottles under air atmosphere in the refrigeration conditions and at ambient temperature. It was established that the autoxidation reaction proceeded very slowly, which is consistent with the results described by Toivonen [39]. The trace amounts of the AHP of 5-10 ppm or 15-20 ppm were detected after ca. 3-5 or 7-9 months, respectively, practically regardless of the temperature of storage of allyl substrate. Moreover, the concentration of AHP did not exceed $30 \mathrm{ppm}$ even after a year. So, the AHP concentration of ca. $25 \mathrm{ppm}$ was finally chosen used for further study. The reaction of 4-allyloxybutan-1-ol containing $25 \mathrm{ppm}$ of AHP with $0.1 \% \mathrm{~mol}$ of the selected ruthenium pre-catalysts was conducted at temperature of $80^{\circ} \mathrm{C}$ or $120^{\circ} \mathrm{C}$ for $0.5 \mathrm{~h}$ or $2 \mathrm{~h}$ under argon atmosphere (Table 1 ). The results for the non-oxidative AHP-free conditions were also added for comparison.

Table 1. The effect of allyl hydroperoxides (AHP) from 4-allyloxybutan-1-ol on the catalytic activity of ruthenium pre-catalyst ${ }^{1}$.

\begin{tabular}{|c|c|c|c|c|c|c|}
\hline \multirow{2}{*}{ Entry } & \multirow{2}{*}{$\begin{array}{c}\text { Pre-Catalyst } \\
0.1 \% \mathrm{~mol} .\end{array}$} & \multirow{2}{*}{$\begin{array}{c}\text { AHP } \\
\text { (ppm) }\end{array}$} & \multicolumn{2}{|c|}{$80^{\circ} \mathrm{C} / 2 \mathrm{~h}$} & \multicolumn{2}{|c|}{$120^{\circ} \mathrm{C} / 2 \mathrm{~h}$} \\
\hline & & & $\alpha(\%)$ & $S_{P}(\%)(\% E)$ & $\alpha(\%)$ & $S_{P}(\%)(\% E)$ \\
\hline 1 & \multirow{2}{*}[\mathrm{RuClH}(\mathrm{CO})(\mathrm{PPh}_{3})_{3}]{} & 0 & $100^{2}$ & $100(39)^{2}$ & $100^{2}$ & $99(41)^{2}$ \\
\hline 2 & & 25 & $100^{2}$ & $100(39)^{2}$ & $100^{2}$ & $98(40)^{2}$ \\
\hline 3 & \multirow{2}{*}[\mathrm{RuClH}(\mathrm{CO})(\mathrm{AsPh}_{3})_{3}]{} & 0 & 100 & $96(56)$ & 100 & $43(51)$ \\
\hline 4 & & 25 & 100 & $98(62)$ & 100 & $25(59)$ \\
\hline 5 & \multirow{2}{*}[\mathrm{RuH}_{2}(\mathrm{CO})(\mathrm{PPh}_{3})_{3}]{} & 0 & 78 & $100(48)$ & 100 & $100(42)$ \\
\hline 6 & & 25 & 52 & $100(63)$ & 92 & $100(42)$ \\
\hline 7 & \multirow{2}{*}[\mathrm{RuCl}_{2}(\mathrm{PPh}_{3})_{3}]{} & 0 & $100^{2}$ & $89(59)^{2}$ & $100^{2}$ & $23(46)^{2}$ \\
\hline 8 & & 25 & $100^{2}$ & $96(53)^{2}$ & $100^{2}$ & $43(44)^{2}$ \\
\hline 9 & \multirow{2}{*}[\mathrm{RuCl}_{2}(\mathrm{CO})_{2}(\mathrm{PPh}_{3})_{2}]{} & 0 & 9 & $90(29)$ & 100 & $26(42)$ \\
\hline 10 & & 25 & 7 & $100(29)$ & 95 & $22(40)$ \\
\hline 11 & \multirow{2}{*}{$\left[\mathrm{RuCl}_{2}(1,5-\mathrm{cod})\right]_{\mathrm{x}}$} & 0 & 84 & $93(89)$ & 100 & $12(76)$ \\
\hline 12 & & 25 & 74 & $94(88)$ & 100 & $20(68)$ \\
\hline 13 & \multirow{2}{*}{$\left[\mathrm{RuCl}_{2}(p-\mathrm{Cym})\right]_{2}$} & 0 & 90 & $32(52)$ & 100 & $3(100)$ \\
\hline 14 & & 25 & 91 & $30(57)$ & 100 & 0 \\
\hline
\end{tabular}

${ }^{1}$ The reaction conditions: 4 mmole scale of allyloxyalcohol, argon atmosphere, magnetic stirrer. ${ }^{2}$ The reaction time: $0.5 \mathrm{~h}$.

As can be seen, the AHP as low concentration as $25 \mathrm{ppm}$ partially reduced or practically no affected on the catalytic activity ruthenium complexes. Among the complexes tested, the most hydroperoxides-sensitive catalyst was formed from $\left[\mathrm{RuH}_{2}(\mathrm{CO})\left(\mathrm{PPh}_{3}\right)_{3}\right]$ - the values of allyl substrate conversion were visibly lower by ca. $30 \%$ at $80{ }^{\circ} \mathrm{C}$ and by ca. $10 \%$ at $120{ }^{\circ} \mathrm{C}$ (entry 6). Therefore, this very selective pre-catalyst, postulated by us previously [21], is not suitable for industrial application. Notably, a very fast reaction with the quantitative conversion within a short time of $30 \mathrm{~min}$ was observed for $\left[\mathrm{RuClH}(\mathrm{CO})\left(\mathrm{PPh}_{3}\right)_{3}\right]$ and $\left[\mathrm{RuCl}_{2}\left(\mathrm{PPh}_{3}\right)_{3}\right]$, but only for the first one was the 1-propenyl product obtained exclusively or almost exclusively (entry 2). Moreover, except for $\left[\mathrm{RuCl}_{2}\left(\mathrm{PPh}_{3}\right)_{3}\right]$ (entry 8), the presence of AHP did no suppress the subsequent reaction of cyclization. Similarly, the effect of AHP on the stereoselectivity was practically negligible. 
On the other hand, it is probable that the relatively high concentration of [Ru] pre-catalyst used $(0.1 \mathrm{~mol} \%)$ masks the real effect of the AHP on the isomerization course. Therefore, in the next series of experiments, for the most effective pre-catalyst of $\left[\mathrm{RuClH}(\mathrm{CO})\left(\mathrm{PPh}_{3}\right)_{3}\right]$ (mainly) and $\left[\mathrm{RuCl}_{2}\left(\mathrm{PPh}_{3}\right)_{3}\right]$, the considerably lower loadings of $0.003 \mathrm{~mol} \% 0.005 \mathrm{~mol} \%$ or $0.01 \mathrm{~mol} \%$ were used on a larger scale (ca. $6.5 \mathrm{~g}$ od allyl substrate) under the similar reaction conditions. The selected results are given in Table 2 and presented in Figure 1.

Table 2. The catalytic activity of $\left[\mathrm{RuClH}(\mathrm{CO})\left(\mathrm{PPh}_{3}\right)_{3}\right]$ in the presence of $25 \mathrm{ppm}$ of the allyl hydroperoxides from 4-allyloxybutan-1-ol: the effect of the minimal [Ru] loadings ${ }^{1}$.

\begin{tabular}{|c|c|c|c|c|c|c|c|}
\hline Entry & [Ru] (mol\%) & $\mathrm{t}\left({ }^{\circ} \mathrm{C}\right)$ & Time (h) & $\alpha(\%)$ & $\mathrm{S}_{\mathrm{P}}(\%)(\% E)$ & TON & TOF $\left(h^{-1}\right)$ \\
\hline 1 & 0.003 & \multirow{4}{*}{80} & 9 & $58^{2}$ & $98(51)$ & 18,947 & 2105 \\
\hline 2 & 0.005 & & 9 & $59^{2}$ & $98(50)$ & 11,564 & 1285 \\
\hline 3 & 0.01 & & 6 & 98 & $98(52)$ & 9604 & 1601 \\
\hline 4 & & & 9 & 99 & $95(56)$ & 9405 & 1045 \\
\hline 5 & 0.003 & \multirow{5}{*}{120} & 3.5 & 99 & $64(37)$ & 21,120 & 6034 \\
\hline 6 & $0.003^{3}$ & & 5 & 90 & $99(33)$ & 29,700 & 5940 \\
\hline 7 & 0.005 & & 3.5 & 99 & $47(46)$ & 9306 & 2659 \\
\hline 8 & $0.005^{3}$ & & 5 & 98 & $99(35)$ & 19,404 & 3881 \\
\hline 9 & $0.005^{3,4}$ & & 3 & 98 & $99(45)$ & 19,404 & 6468 \\
\hline
\end{tabular}

${ }^{1}$ The reaction conditions: 50 mmole scale of allyloxyalcohol, argon atmosphere, magnetic stirrer. ${ }^{2}$ No further reaction was observed. ${ }^{3}$ The catalytic system: $[\mathrm{Ru}]+\mathrm{Bu}_{3} \mathrm{~N}$. ${ }^{4}$ The concentration of allyl hydroperoxides: 5-10 ppm.

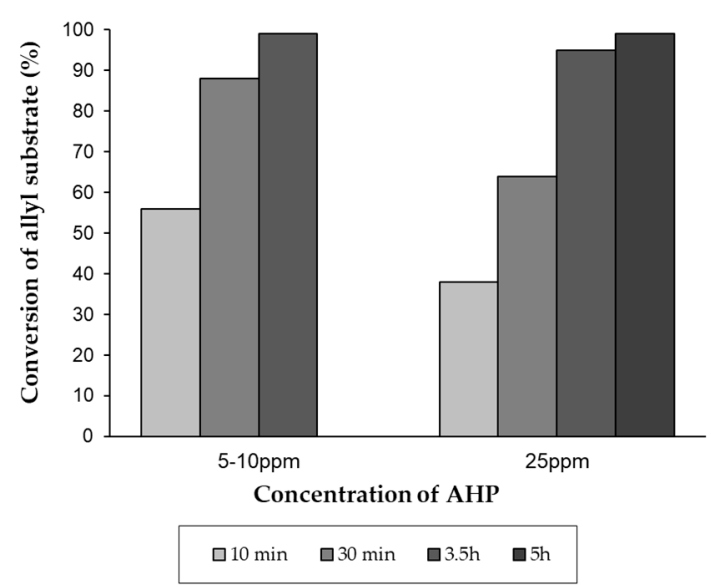

(a)

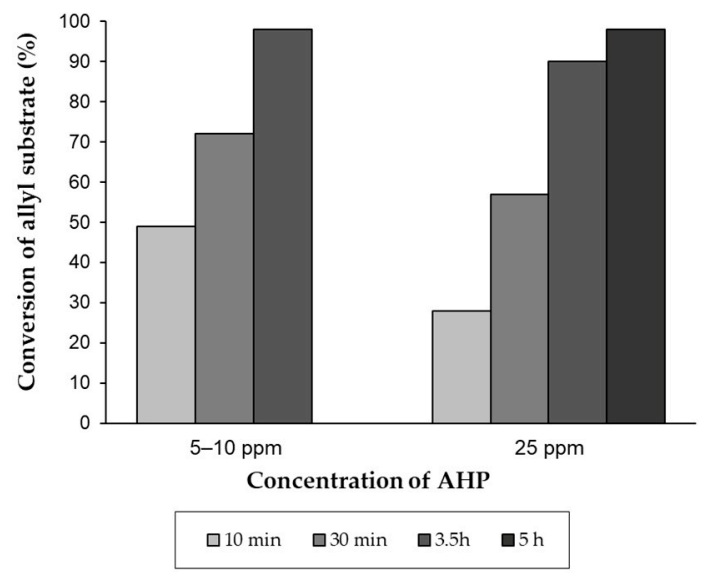

(b)

Figure 1. The effect of concentration of allyl hydroperoxides (AHP) from 4-allyloxybutan-1-ol on the catalytic activity (a) $\left[\mathrm{RuClH}(\mathrm{CO})\left(\mathrm{PPh}_{3}\right)_{3}\right]+\mathrm{Bu}_{3} \mathrm{~N}$ or $(\mathbf{b})\left[\mathrm{RuCl}_{2}\left(\mathrm{PPh}_{3}\right)_{3}\right]+\mathrm{Bu}_{3} \mathrm{~N}$ in the isomerization to $(\mathrm{Z})$ and (E)-4-(1-propenyloxy)butan-1-ol (the reaction conditions: scale $50 \mathrm{mmol}, 120^{\circ} \mathrm{C},[\mathrm{Ru}]=0.005 \mathrm{~mol} \%$, $\mathrm{Bu}_{3} \mathrm{~N} /[\mathrm{Ru}]$ molar ratio $=50$, argon atmosphere, magnetic stirrer).

Unfortunately, in all cases, the AHP inhibited the isomerization rate, mainly at a moderate temperature of $80{ }^{\circ} \mathrm{C}$ (entries 1-4) or in the first step of the reaction at $120{ }^{\circ} \mathrm{C}$ (Figure 2). At $80{ }^{\circ} \mathrm{C}$, with $0.003 \mathrm{~mol} \%$ or $0.005 \mathrm{~mol} \%$ of $\left[\mathrm{RuClH}(\mathrm{CO})\left(\mathrm{PPh}_{3}\right)_{3}\right]$, the reaction was stopped after $9 \mathrm{~h}$ with the yield of 1-propenyloxyalcohol of only ca. 60\% (entries 1 and 2). However, the relatively low loading of the complex of $0.01 \mathrm{~mol} \%$ was enough to achieve a high yield of 1-propenyl product (96\%) with high TON (9604) within $6 \mathrm{~h}$ (entries 3). The further prolongation of reaction time to $9 \mathrm{~h}$ was adverse due to slight loss of reaction selectivity and in consequence, the yield of the main product (entries 4). An increase in the reaction temperature up to $120^{\circ} \mathrm{C}$ significantly accelerated the reaction rate and the loading of $0.003 \mathrm{~mol} \%$ or $0.005 \mathrm{~mol} \%$ of the $\left[\mathrm{RuClH}(\mathrm{CO})\left(\mathrm{PPh}_{3}\right)_{3}\right]$ was enough to obtain a practically quantitative conversion within only $3.5 \mathrm{~h}$ (entries 5 and 7). Simultaneously, under these conditions the allyl hydroperoxide itself was not able to keep the reaction in the double bond migration step 
selective (entries 5 and 7) and the $\mathrm{Bu}_{3} \mathrm{~N}$ (chosen from the organic and inorganic bases verified by us previously [21]) was necessary to reduce the progress of the cyclization reaction [21]. Although the incorporation of $\mathrm{Bu}_{3} \mathrm{~N}$ slightly reduced the isomerization reaction rate, we determined the high catalytic efficiency of catalyst with obtaining $90 \%$ or almost $100 \%$ yield and high values of TON of 29,700 or 19,404 (for [Ru loadings of $0.003 \mathrm{~mol} \%$ or $0.005 \mathrm{~mol} \%$, respectively) within the reaction time of $5 \mathrm{~h}$ (entries 6 and 8). However, even though the high TON of 29,700 was noted it is obvious that the yield of $90 \%$ could be insufficient for obtaining a pure product. Due to the small difference in the values of the 1-propenyl and allyl ethers boiling points under reduced pressure, successful separation and purification of 1-propenyl product from allyl substrate via conventional vacuum distillation could be difficult from the technological point of view.

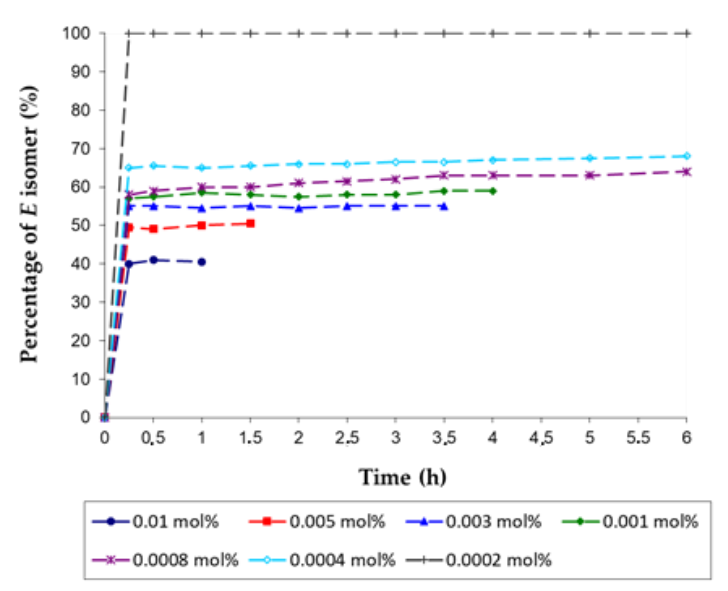

(a)

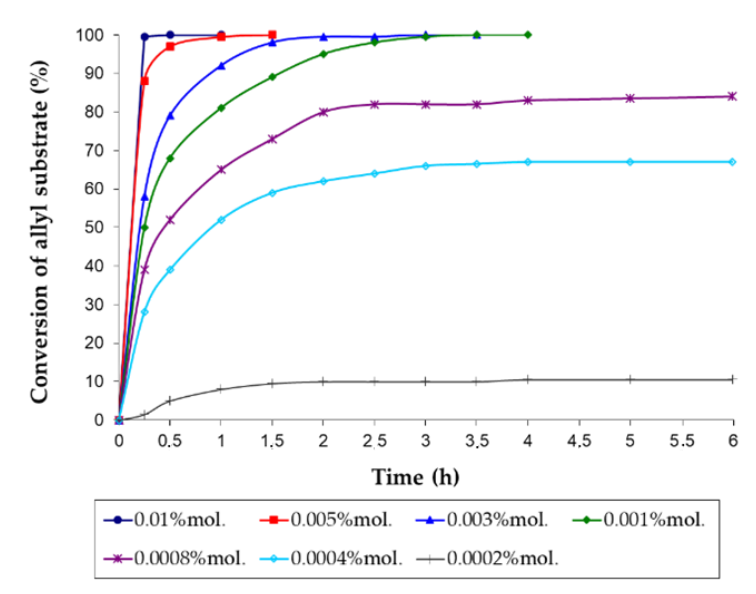

(b)

Figure 2. The effect of the $\left[\mathrm{RuClH}(\mathrm{CO})\left(\mathrm{PPh}_{3}\right)_{3}\right]$ pre-catalyst concentration on the isomerization of the hydroperoxide-free 4-allyloxybutan-1-ol to (Z)- and (E)-4-(1-propenyloxy)butan-1-ol: (a) variation of the allyloxyalcohol conversion and $(\mathbf{b})$ variation of the reaction stereoselecivity to $E$-1-propenyl isomer (the reaction conditions: scale $150 \mathrm{mmol}, 80^{\circ} \mathrm{C}$, argon atmosphere, magnetic stirrer).

Moreover, at $120{ }^{\circ} \mathrm{C}$ we compared the catalytic activity of $\left[\mathrm{RuClH}(\mathrm{CO})\left(\mathrm{PPh}_{3}\right)_{3}\right]+\mathrm{Bu}_{3} \mathrm{~N}$ $\left[\mathrm{RuCl}_{2}\left(\mathrm{PPh}_{3}\right)_{3}\right]+\mathrm{Bu}_{3} \mathrm{~N}$ in the presence of $25 \mathrm{ppm}$ and also 5-10 ppm. Firstly, we found that even traces of AHP of 5-10 ppm affected the catalytic activity of ruthenium catalysts, especially in the first step of the reaction (up to ca. $10 \mathrm{~min}$ ), but the reaction carried on relatively fast within $3 \mathrm{~h}$ until a high yield of 1-propenyloxyalcohol was attained (Figure 1). Secondly, it was very surprising that under identical conditions, regardless of the ruthenium precursor, the practically the same results were practically obtained (Figure 1a,b), which suggests that very similar or even the same active forms of the catalyst are formed in both reaction systems. Although the tested ruthenium catalysts were found to be sensitive under oxidative conditions, indicating the disruption in the process of generating an active form of the catalyst and/or transforming the ruthenium complex into less active species, the application of suitable relatively low loadings of pre-catalysts allowed to conduct the highly yielded synthesis of 1-propenyloxybutan-1-ol.

Intending to further confirm the technological usefulness of these ruthenium pre-catalyst, we continued carefully optimization of process parameters under non-oxidative reaction conditions with using the AHP-free allyl substrate. Again, we started from conducting the isomerization reaction at the temperature of $80^{\circ} \mathrm{C}$ with neat $\left[\mathrm{RuClH}(\mathrm{CO})\left(\mathrm{PPh}_{3}\right)_{3}\right]$ in the range of minimal pre-catalyst concentration of $0.0002-0.01 \mathrm{~mol} \%$ (2-100 ppm) on a larger scale (ca. $20 \mathrm{~g}$ of allyl substrate). The selected results were collected in Table 3 and also depicted in Figure 2. 
Table 3. The effectiveness of $\left[\mathrm{RuClH}(\mathrm{CO})\left(\mathrm{PPh}_{3}\right)_{3}\right]$ in the solvent-free isomerization of the AHP-free 4-allyloxybutan-1-ol to (Z)- and (E)-4-(1-propenyloxy)butan-1-ol: the effect of the [Ru] loadings ${ }^{1}$.

\begin{tabular}{ccccccc}
\hline Entry & {$[\mathbf{R u}](\mathbf{m o l} \mathbf{\%})$} & Time & $\boldsymbol{\alpha}(\mathbf{\%})$ & $\mathbf{S}_{\mathbf{P}}(\mathbf{\%}) \mathbf{( \% E )}$ & TON & TOF $\left.\mathbf{h}^{-\mathbf{1}}\right)$ \\
\hline 1 & 0.01 & $15 \mathrm{~min}$ & 99.5 & $100(40)$ & 9950 & 39,800 \\
2 & & $30 \mathrm{~min}$ & 100 & $100(41)$ & 10,000 & 20,000 \\
3 & 0.005 & $1 \mathrm{~h}$ & 100 & $100(51)$ & 20,000 & 20,000 \\
4 & 0.003 & $2 \mathrm{~h}$ & 99 & $100(55)$ & 33,000 & 16,500 \\
5 & & $3 \mathrm{~h}$ & 100 & $100(55)$ & 33,333 & 11,111 \\
6 & 0.001 & $2.5 \mathrm{~h}$ & 98 & $100(58)$ & 98,000 & 39,200 \\
7 & & $3 \mathrm{~h}$ & 100 & $100(58)$ & 100,000 & 33,333 \\
8 & & $3.5 \mathrm{~h}$ & 100 & $99(59)$ & 99,000 & 28,286 \\
9 & 0.0008 & $2 \mathrm{~h}$ & 79.5 & $98(61)$ & 97,388 & 48,694 \\
10 & & $5 \mathrm{~h}$ & 86 & $92(63)$ & 98,900 & 19,780 \\
11 & 0.0004 & $2 \mathrm{~h}$ & 62 & $96(66)$ & 148,800 & 74,400 \\
12 & & $6 \mathrm{~h}$ & 672 & $91(68)$ & 152,425 & 25,404 \\
13 & 0.0002 & $6 \mathrm{~h}$ & $10^{2}$ & $79(100)$ & 39,500 & 6583 \\
\hline
\end{tabular}

${ }^{1}$ The reaction conditions: $150 \mathrm{mmol}$ scale of allyloxyalcohol, $80^{\circ} \mathrm{C}$, argon atmosphere, magnetic stirrer. ${ }^{2}$ No further reaction was observed.

It was found that the reaction occurred quickly in the presence of a relatively low [Ru] loading of $0.01 \mathrm{~mol} \%$ and high TON and TOF values of approximately 9950 and $39,800 \mathrm{~h}^{-1}$ or 10,000 and $20,000 \mathrm{~h}^{-1}$ were obtained within $15 \mathrm{~min}$ or $30 \mathrm{~min}$, respectively (entries 1 and 2 in Table 3). Excellent results were also determined for $0.005 \mathrm{~mol} \%$ of the pre-catalyst with TON and TOF values as high as 20,000 and $20,000 \mathrm{~h}^{-1}$ (entry 3). Further lowering of the [Ru] pre-catalyst amount to $0.003 \mathrm{~mol} \%$ required a 2- or 3 -fold extension of the reaction time, still allowing to receive a $100 \%$ yield of 1-propenyloxyalcohol, with a complete preservation of the selectivity of the reaction (entries 4 and 5), which is important.

Spectacular results were determined for $0.001 \mathrm{~mol} \%(10 \mathrm{ppm})$ of $\left[\mathrm{RuClH}(\mathrm{CO})\left(\mathrm{PPh}_{3}\right)_{3}\right]($ entries 6-8), however, then the reaction course had to be carefully controlled, because the traces of cyclic acetal (2-ethyl-1,3-dioxepane) were observed for prolonged reaction times (entry 8). Nevertheless, a highly yielding and highly reproducible synthesis of the 1-propenyl product could be achieved within $3 \mathrm{~h}$ of the reaction time with very high values of TON and TOF, reaching 100,000 and 33,333 $\mathrm{h}^{-1}$, respectively (entry 7). However, the use of low amounts of this [Ru] complex in the studied range of 0.0004-0.0008 mol\% (4-8 ppm) was insufficient to obtain high yields of 1-propenyloxyalcohol (entries 9-13). Even though in these conditions the reaction time was prolonged to 5-6 h, relatively low allyl substrate conversions were determined (entries 10 and 12-13 and Figure 2a.

Moreover, in the presence of $4 \mathrm{ppm}$ of the pre-catalyst the reaction practically stopped after $6 \mathrm{~h}$ when only ca. $67 \%$ of the allyl substrate was converted (entry 12). Similarly, the desirable catalytic activity for $0.0002 \mathrm{~mol} \%$ (2 ppm) of the pre-catalyst could be not achieved, resulting in a very low conversion of $10 \%$, which remained practically unchanged already after $2 \mathrm{~h}$ of the reaction time (Figure 2a and in a low selectivity of 79\%, achieved after $6 \mathrm{~h}$ (entry 13). It is significant to note that the traces of the cyclic acetal were detected nearly at the beginning of the reaction (entries 9-13). Thus, at a moderate reaction temperature of $80^{\circ} \mathrm{C}$ and at very low loadings of $\left[\mathrm{RuClH}(\mathrm{CO})\left(\mathrm{PPh}_{3}\right)_{3}\right](2-8 \mathrm{ppm})$, the double-bond migration ran too slowly and, in consequence, it was impossible to conduct a selective synthesis of 1-propenyl product.

In our experiments, some pronounced differences in the stereoselectivity of the isomerization reaction were also found, depending on the pre-catalyst loading, suggesting that the stereochemistrycontrolling step occurs in the coordination sphere of the ruthenium. (Figure 1b). Generally, it is well-known from the literature that the double-bond migration of alkenes $[6,8,34]$ and allyl ether $[7,16]$ catalyzed by $\left[\mathrm{RuClH}(\mathrm{CO})\left(\mathrm{PPh}_{3}\right)_{3}\right]$ and other hydride ruthenium catalysts dominantly runs via the hydride addition-elimination mechanism with the preferential kinetic controlled $Z$ isomer formation. Simultaneously the hydride ruthenium complexes are active catalyst in the $Z-E$ or $E-Z$ isomerization, accompanied the double bond migration $[7,8]$. 
Therefore, as might have been expected, when high loading of $\left[\mathrm{RuClH}(\mathrm{CO})\left(\mathrm{PPh}_{3}\right)_{3}\right]$ of $0.01 \mathrm{~mol} \%$ was used, the Z-isomer was the major product of the isomerization (ca. $60 \%$, Figure $1 \mathrm{~b}$ and entries 1 and 2 in Table 3). On the other hand, the gradual increase of the amount of the thermodynamically favored $E$-isomer from $51 \%$ up to $68 \%$ was determined with the decrease of the pre-catalyst concentration from 50 down to $4 \mathrm{ppm}$ (Figure 1b, entries 3-12), whereas in the presence of $2 \mathrm{ppm}$ of [Ru] only the $E$-isomer was formed (Figure 1b, entry 13). What is important, in all post-reaction mixtures, the ca. $15 \mathrm{~min}$. ratio of the $Z$ and $E$ isomers remained almost unchanged during further reactions (Figure $1 \mathrm{~b}$ ). Thus, practically no subsequent $Z-E$ nor $E-Z$ isomerization was observed. As can be seen, these nearly equimolar compositions of $Z$ and $E$ isomers were significantly affected by [Ru] loadings. Consequently, it is probable that the active forms of real catalyst formed very fast at the beginning of reaction.

Although details of the active species structure remain unexplained, there is no doubt that in the first step, very labile and bulky $\mathrm{PPh}_{3}$ ligands undergo a fast dissociation from the $\mathrm{Ru}$ center. Additionally, the decreasing of the pre-catalyst concentration caused the growing extent of their dissociation in the allyl substrate solution, resulting in a decreasing steric hindrance of the formed catalytically electron poor active species [40] and accelerated the formation of the thermodynamically favored $E$ isomer. On the other hand, in the case of the studied allyloxyalcohol isomerization catalyzed by very low loadings of [Ru] (below $10 \mathrm{ppm}$ ), the loss of the $\mathrm{Z}$ isomer could also be partially connected with the following cyclization, because, as we demonstrated previously, the $Z$ isomer undergoes the cyclization much faster than the corresponding $E$ isomer [21].

For the further optimization of isomerization process parameters, we explored the catalytic activity of $\left[\mathrm{RuClH}(\mathrm{CO})\left(\mathrm{PPh}_{3}\right)_{3}\right]$ with the minimal pre-catalyst loading of $0.0002 \mathrm{~mol} \%, 0.0003 \mathrm{~mol} \%$ or 0.0005 $\mathrm{mol} \%(2,3$ or $5 \mathrm{ppm})$ under harsher temperature conditions of $100{ }^{\circ} \mathrm{C}$ or $120{ }^{\circ} \mathrm{C}$. The practically significant results essential to depict catalytic behavior were selected and presented in Table 4 . In these experiments, the presence of a base such as $\mathrm{Bu}_{3} \mathrm{~N}$ was absolutely required to eliminate the cyclization reaction (compare entries 1 and 2 in Table 4).

Table 4. The effectiveness of $\left[\mathrm{RuClH}(\mathrm{CO})\left(\mathrm{PPh}_{3}\right)_{3}\right]$ ([Ru-1]) and $\left[\mathrm{RuCl}_{2}\left(\mathrm{PPh}_{3}\right)_{3}\right]$ ([Ru-2]) in the solvent-free isomerization of hydroperoxide-free -free 4-allyloxybutan-1-ol to (Z)- and (E)-4-(1-propenyloxy)butan-1-ol: the optimization of the reaction conditions ${ }^{1}$.

\begin{tabular}{cccccccc}
\hline Entry & Pre-Catalyst & $\boldsymbol{t}\left({ }^{\circ} \mathbf{C}\right)$ & Time (h) & $\boldsymbol{\alpha}(\mathbf{\%})$ & $\mathbf{S}_{\mathbf{P}}(\mathbf{\%}) \mathbf{( \% E )}$ & $\mathbf{T O N}$ & TOF $\left(\mathbf{h}^{-\mathbf{1}}\right)$ \\
\hline 1 & {$[\mathrm{Ru}-1]$} & 100 & 9 & 98 & $8(51)$ & 15,680 & 1742 \\
2 & {$[\mathrm{Ru}-1]+\mathrm{Bu}_{3} \mathrm{~N}$} & 100 & 9 & 99.5 & $99.5(31)$ & 198,000 & 22,000 \\
3 & {$[\mathrm{Ru}-1]+\mathrm{Bu}_{3} \mathrm{~N}$} & 120 & 0.5 & 98.5 & $100(45)$ & $\mathbf{1 9 7 , 0 0 0}$ & $\mathbf{3 9 4 , 0 0 0}$ \\
4 & & & 1 & 99.3 & $99.5(45)$ & 197,607 & 197,607 \\
5 & {$[\mathrm{Ru}-2]^{2}$} & 100 & 3 & 94 & $13(76)$ & 2444 & 815 \\
6 & {$[\mathrm{Ru}-2]^{2}+\mathrm{Bu}_{3} \mathrm{~N}$} & 100 & 3 & 97.5 & $99(43)$ & 19,305 & 6435 \\
7 & {$[\mathrm{Ru}-2]+\mathrm{Bu}_{3} \mathrm{~N}$} & 120 & 0.5 & 98.3 & $100(50)$ & $\mathbf{1 9 6 , 0 0 0}$ & $\mathbf{3 9 2 , 0 0 0}$ \\
8 & & & 1 & 99.5 & $99.9(48)$ & 198,801 & 198,801 \\
\hline
\end{tabular}

1 The reaction conditions: $150 \mathrm{mmol}$ scale of allyloxyalcohol, $[\mathrm{Ru}]=0.0005 \mathrm{~mol} \%(5 \mathrm{ppm}), \mathrm{Bu} 3 \mathrm{~N} /[\mathrm{Ru}] \mathrm{molar}$ ratio $=50$, argon atmosphere, magnetic stirrer. ${ }^{2}[\mathrm{Ru}]=0.005 \mathrm{~mol} \%(50 \mathrm{ppm})$.

It was clear that at $100{ }^{\circ} \mathrm{C}$, the isomerization catalyzed by $\left[\mathrm{RuClH}(\mathrm{CO})\left(\mathrm{PPh}_{3}\right)_{3}\right]+\mathrm{Bu}_{3} \mathrm{~N}$ catalytic system could proceeded with practically quantitative yield of 1-propenyloxybutanol $(99 \%)$ and relatively high values of TON of 198,000, but within the unfavorable long reaction time of $9 \mathrm{~h}$, which gave a TOF of 22,000 $\mathrm{h}^{-1}$ (entry 2). Nevertheless, we did not observe any oligomerization during prolongated heating of reaction mixture. Encouraged by this finding, we conducted the reaction at a higher temperature of $120^{\circ} \mathrm{C}$. First, it was found that utilizing very low ruthenium complex loadings of $0.0002 \mathrm{~mol} \%$ or $0.0003 \mathrm{~mol} \%$ ( $2 \mathrm{pm}$ or $3 \mathrm{ppm}$ ) provided unsatisfactory results, namely the conversion values of $46 \%$ or $68 \%$, respectively, after $5 \mathrm{~h}$ (not shown). Surprisingly, at the [Ru] concentration of $0.0005 \mathrm{~mol} \%(5 \mathrm{ppm})$ the isomerization ran spectacularly fast and selectively, leading to the extremely high TON and TOF values of 197,000 and $394,000 \mathrm{~h}^{-1}$ in very short reaction time of $0.5 \mathrm{~h}$ or 197,607 and $197,607 \mathrm{~h}^{-1}$ in $1 \mathrm{~h}$ (entries 3 and 4 ) - the highest ones reported to date for 
this catalytic transformation of allyl ethers to their 1-propenyl derivatives. So, this result confirms very high productivity of discovered catalytic system, comparable to the rhodium complex such as [Rh(-)-BINAP(COD) $\mathrm{ClO}_{4}$ used in the industry for the isomerization of $\mathrm{N}$-allyl system to $\mathrm{N}$-1-propenyl derivative in the synthesis of (-)-menthol (here TON $=400,000$, TOF $=1300 / \mathrm{h}$ were achieved after proper preparation of the substrate and the catalyst recycling [11]). Moreover, these results were shown the key effect of temperature reaction on the activation of homogeneous ruthenium catalyst formed under reaction conditions. We observed that the raising of reaction temperature only by $20{ }^{\circ} \mathrm{C}$ had a dramatic effect on the rate of the isomerization reaction, giving a rate enhancement of ca. 18 times. The similar behaviour was observed for $\left[\mathrm{RuCl}_{2}(\mathrm{CO})_{2}\left(\mathrm{PPh}_{3}\right)_{2}\right]$ (Entries 9 and 10 in Table 1), which was almost inactive at temperature of $80^{\circ} \mathrm{C}$ in contrast to its efficacy at temperature of $120^{\circ} \mathrm{C}$.

Simultaneously, we want to investigate the effectiveness of $\left[\mathrm{RuCl}_{2}\left(\mathrm{PPh}_{3}\right)_{3}\right]$ in the presence of $\mathrm{Bu}_{3} \mathrm{~N}$ under the same non-oxidative conditions. Firstly, at a lower reaction temperature of $80{ }^{\circ} \mathrm{C}$, this non-hydride neat pre-catalyst was much less active than the hydride $\left[\mathrm{RuClH}(\mathrm{CO})\left(\mathrm{PPh}_{3}\right)_{3}\right]$. For example, it was determined that the use of $0.005 \mathrm{~mol} \%$ (50 ppm) of $\left[\mathrm{RuCl}_{2}\left(\mathrm{PPh}_{3}\right)_{3}\right]$ gave the yield of 1-propenyloxybutanol of only ca. $53 \%$ after $1 \mathrm{~h}$ (not shown), whereas for $\left[\mathrm{RuClH}(\mathrm{CO})\left(\mathrm{PPh}_{3}\right)_{3}\right]$ the full yield was attained under the same conditions (entry 3 in Table 3). However, performing the isomerization at the higher reaction temperature of $100{ }^{\circ} \mathrm{C}$ in the presence of $\mathrm{Bu}_{3} \mathrm{~N}$ caused a substantial increase in the activity of this pre-catalyst with an almost complete conversion and selectivity to 1-propenyl derivative in $3 \mathrm{~h}$ (entry 6). In accordance with our results presented above in Figure 1 (at the higher reaction temperature the catalytic activity of $\left[\mathrm{RuCl}_{2}\left(\mathrm{PPh}_{3}\right)_{3}\right]+\mathrm{Bu}_{3} \mathrm{~N}$ was comparable to $\left.\left[\mathrm{RuClH}(\mathrm{CO})\left(\mathrm{PPh}_{3}\right)_{3}\right]+\mathrm{Bu}_{3} \mathrm{~N}\right)$, the reaction was conducted at $120^{\circ} \mathrm{C}$, and the loading of $\left[\mathrm{RuCl}_{2}\left(\mathrm{PPh}_{3}\right)_{3}\right]$ was decreased to $0.0005 \mathrm{~mol} \%$ (5 ppm) (entries 7 and 8). Again, the efficiency of $\left[\mathrm{RuCl}_{2}\left(\mathrm{PPh}_{3}\right)_{3}\right]+\mathrm{Bu}_{3} \mathrm{~N}$ catalytic system was surprisingly similar to $\left[\mathrm{RuClH}(\mathrm{CO})\left(\mathrm{PPh}_{3}\right)_{3}\right]+\mathrm{Bu}_{3} \mathrm{~N}$ and unprecedentedly high with TON of 196,000 and TOF of $394,000 \mathrm{~h}^{-1}$ after $0.5 \mathrm{~h}$ (entry 7) or with TON of 198,801 and TOF of $198,801 \mathrm{~h}^{-1}$ after $1 \mathrm{~h}$ (entry 8).

A plausible explanation is that in both reaction systems the similar enormously active forms of the catalyst must have been generated in situ, probably hydride ruthenium complexes-the most effective catalysts in double bond migration $[7,8]$. It is well-known that the hydride ruthenium catalysts are easily generated in situ from simple complexes containing hydride ligand (such as $\left.\left[\mathrm{RuClH}(\mathrm{CO})\left(\mathrm{PPh}_{3}\right)_{3}\right]\right)$ or from $[\mathrm{Ru}]+$ hydride ligand donor catalytic system $[7,8]$ (optionally with catalyst activator: base), especially from $\left[\mathrm{RuCl}_{2}\left(\mathrm{PPh}_{3}\right)_{3}\right]$ with alcohol as hydride ligand donor and inorganic base ( $\mathrm{KOH}, \mathrm{K}_{2} \mathrm{CO}_{3}$ [33]) or organic base (amines [21]) as activator. Most importantly, they are presumably formed very fast during the first step of reaction (up to ca. $4-5 \mathrm{~min}$ ), which partially explains its extremely fast course. A few arguments appear to support this hypothesis. First of all, during the first five minutes of heating, we observed a fast dissolution of the [Ru] complexes together with a rapid change of the color of reaction mixtures to clear light yellow, especially visible for the initially dark brown of $\left[\mathrm{RuCl}_{2}\left(\mathrm{PPh}_{3}\right)_{3}\right]$. Furthermore, because isomerization of allyl ethers is a slightly exothermic process with the enthalpy values ranging from ca. -18 to $-25 \mathrm{~kJ} / \mathrm{mol}$ [41] and, as we demonstrated recently [18], the thermal effect can be induced during reaction, we shifted our focus to continuous measurements of the reaction mixture temperature during heating. It was found that in the range of reaction time of 5 to $7-8 \mathrm{~min}$, the reaction of 4-allyloxybutan-1-ol with $\left[\mathrm{RuClH}(\mathrm{CO})\left(\mathrm{PPh}_{3}\right)_{3}\right]+\mathrm{Bu}_{3} \mathrm{~N}$ or $\left[\mathrm{RuCl}_{2}\left(\mathrm{PPh}_{3}\right)_{3}\right]+\mathrm{Bu}_{3} \mathrm{~N}$ occurred with exothermic effect as high as ca. $25^{\circ} \mathrm{C}$ (Figure 3). Thus, in both reaction systems, the high conversion values of allyl substrate ca. $90 \%$ were reached after $15 \mathrm{~min}$ of reaction.

There is no doubt that the rise in the reaction mixture temperature is primarily related to the exothermic nature of the isomerization reaction as well as with its violent run under the employed reaction conditions. The theoretical value of the enthalpy of the reaction at standard conditions $\left(\Delta H^{0}{ }_{r}\right)$ equals $-8.21 \mathrm{~kJ} / \mathrm{mol}$ (calculated with using values of standard enthalpy of formation allyl substrate and 1-propenyl product given in ChemBioDraw Ultra 13.0 Cambridge software). In summary, recognizing our findings and relatively low value of $\Delta H^{0}{ }_{r}$, it is reasonable to suggest that the extremely active 
ruthenium catalyst, formed from traces in the amount of $5 \mathrm{ppm}[\mathrm{Ru}]$ in the presence of amine $\mathrm{Bu}_{3} \mathrm{~N}$ as activator, caused the very vigorous course of isomerization with high TOF of ca. $3.9 \cdot \times 10^{5} \mathrm{~h}^{-1}$ (but not so high to cause runaway reactions). Nevertheless, the specific temperature effects are not fully understood, although there is an indication that an appropriate well-determined reaction temperature does substantially influence on the catalyst activity and reaction rate. Moreover, to our knowledge, the thermal effects induced during double-bond isomerization reaction of allyl systems are completely overlooked in the literature.

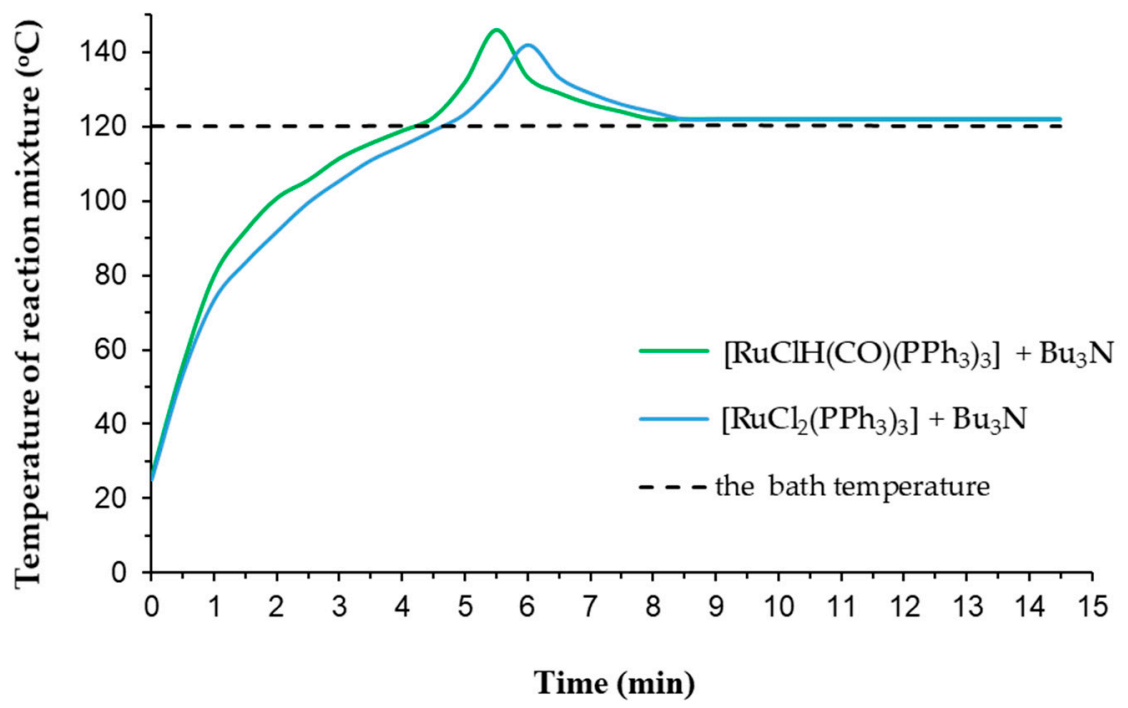

Figure 3. The changes of temperature of reaction mixture in the first step of the solvent-free reaction of hydroperoxide-free 4-allyloxybutan-1-ol with $\left[\mathrm{RuClH}(\mathrm{CO})\left(\mathrm{PPh}_{3}\right)_{3}\right]+\mathrm{Bu}_{3} \mathrm{~N}$ and $\left.\left[\mathrm{RuCl}_{2} \mathrm{PPh}_{3}\right)_{3}\right]+\mathrm{Bu}_{3} \mathrm{~N}$ (the reaction conditions: $150 \mathrm{mmol}$ scale of allyloxyalcohol, $[\mathrm{Ru}]=0.0005 \mathrm{~mol} \%$ (5 ppm), Bu $3 \mathrm{~N} /[\mathrm{Ru}]$ molar ratio $=50$, argon atmosphere, magnetic stirrer.).

As was mentioned in the introduction, there are two basic approaches to increasing catalyst productivity in the field of practical homogeneous catalysis with soluble transition metal complexes (TMCs). The first is to use active catalysts at the minimum load that will bring a reaction to completion (which we demonstrated above). Then, the spent and partially decomposed catalysts are usually sent to the producer for precious metal recovering, reclaiming and refining. The second way is recycling of catalyst dedicated to the bath mode systems if the suitable method of catalysts separation from the product without loss of their stability is possible. Various methods and strategies for the recycling and reuse of homogeneous catalysts have been reported [8,42], but recycling is rarely practiced in fine chemical production, as the extra unit operations involved does not outweigh the gains of a reuse of the catalyst $[4,5]$. However, the homogeneous reactions that have been commercialized involve simple common methods separation such as the distillation of the product above catalyst, not containing thermally sensitive organic ligands. To our the best knowledge, in contrast to improved methods of catalyst separation and reuse, in particular through heterogenization of homogeneous catalysts, except for our previous works $[17,18]$ the direct homogeneous catalyst recycling is barely mentioned in the literature $[2,42,43]$.

Therefore, in order to verify the catalyst productivity in the studied process we finally explored the direct recycling of ruthenium catalyst with low-temperature vacuum distillation of the main 1-propenyloxyalcohol product. This method relies on the conducting subsequent cycles of reaction-distillation under nearly the same conditions without additional promoters and unit operations (e.g., precipitation and purification of the catalyst) up to a significant decrease in the reaction yield, indicating catalyst deactivation. According that under mild reaction conditions the high catalytic activity was confirmed for $\left[\mathrm{RuClH}(\mathrm{CO})\left(\mathrm{PPh}_{3}\right)_{3}\right]$ (Table 3$)$ we conduct the catalyst recycling with using 
AHP-free 4-allyloxybunan-1-ol and the $\left[\mathrm{RuClH}(\mathrm{CO})\left(\mathrm{PPh}_{3}\right)_{3}\right]$ precursor concentration of $0.1 \mathrm{~mol} \%$ at $80{ }^{\circ} \mathrm{C}$ under argon atmosphere and magnetic stirring. The monitoring of reaction progress as well as the reaction mixture temperature was be carried out during the research. The obtained results given as TON, TOF and the maximal values of reaction mixture temperature are presented in Figure 4.

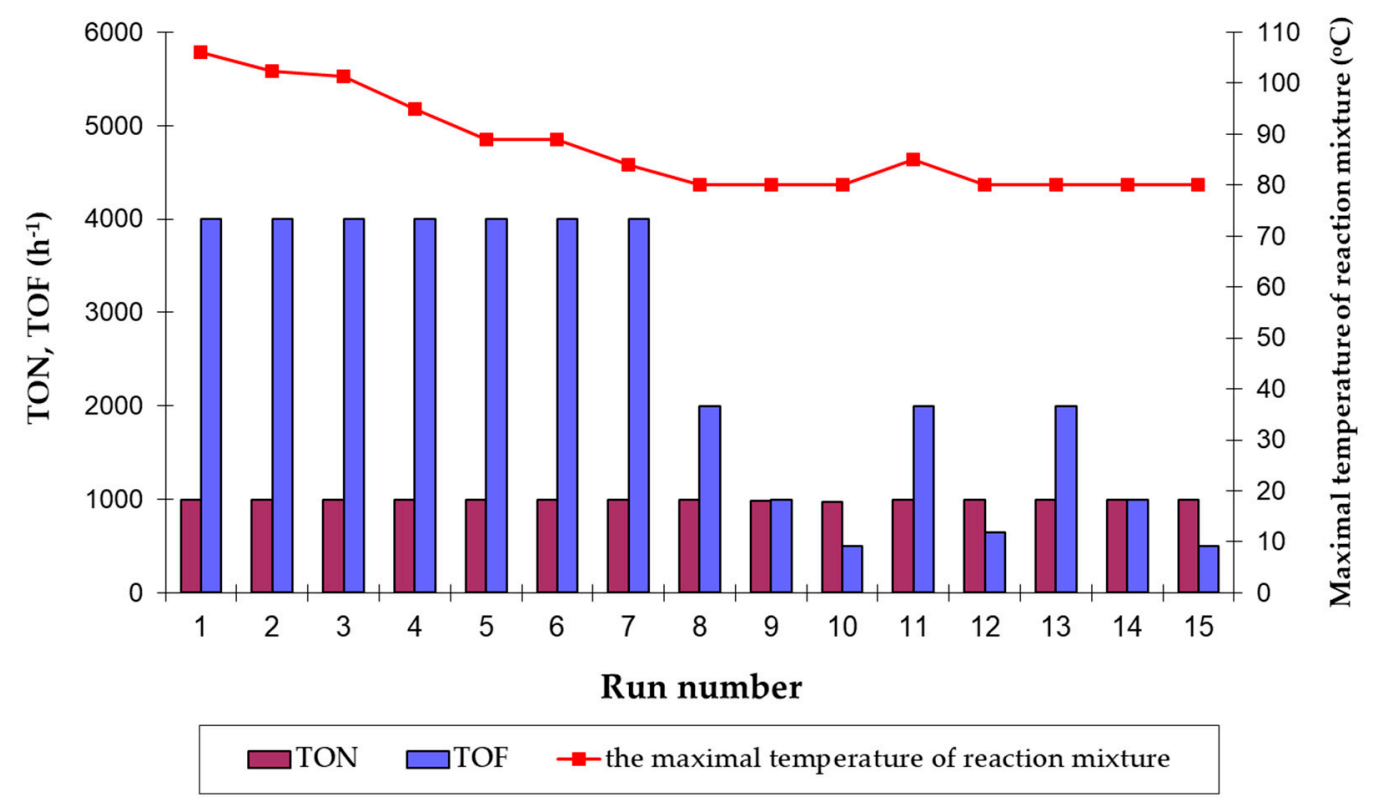

Figure 4. The effectiveness of the recycling catalyst formed from $\left[\mathrm{RuClH}(\mathrm{CO})\left(\mathrm{PPh}_{3}\right)_{3}\right]$ and the maximal values of the reaction mixture temperature achieved during the isomerization of hydroperoxide-free 4-allyloxybutan-1-ol to (Z)- and (E)-4-(1-propenyloxy)butan-1-ol (the reaction conditions: scale $50 \mathrm{mmol}$, $80{ }^{\circ} \mathrm{C},[\mathrm{Ru}]=0.1 \mathrm{~mol} \%$, argon atmosphere, magnetic stirrer, K-type thermocouple; Runs 11 and 13-15: fresh portion of $\mathrm{Et}_{3} \mathrm{~N}$ in molar ratio $\mathrm{Et}_{3} \mathrm{~N} /[\mathrm{Ru}]=10$ was added).

As can be seen, the catalyst formed in situ from the neat $\left[\mathrm{RuClH}(\mathrm{CO})\left(\mathrm{PPh}_{3}\right)_{3}\right]$ could be reused for as many as seven consecutive cycles with the same highest catalytic activity-in each cycle the yield of 1-propenyloxyalcohol was practically quantitative after $15 \mathrm{~min}$ only with the productivity at the level of ca. 1000 (TON) and $4000 \mathrm{~h}^{-1}$ (TOF) (Runs 1-7 in Figure 4). Thereafter, the isomerization rate decreased constantly as demonstrated in the prolonged reaction time experiments up to $2 \mathrm{~h}$ (Run 10), and TOF values dropped significantly from $4000 \mathrm{~h}^{-1}$ (Run 7) to only $500 \mathrm{~h}^{-1}$ (Run 10). Starting with Run 8 , we observed the change of the color of reaction mixtures from clear light yellow via light orange to orange-red. So, the intrinsic instability caused partial decomposition of the hydride ruthenium catalyst seems to be responsible for its lower activity (the ways of homogeneous triphenylphosphine hydride catalysts decomposition are presented in detail in [37]). Therefore, $\mathrm{Et}_{3} \mathrm{~N}$ was introduced into the reaction systems (Run 11), considering Bäckvall's findings about the key role of bases in the formation (or reproduction) of the hydride (or dihydride) active species of the catalyst in the presence of alcohols as hydride ligand [33], and also the remarkable accelerating effect of amines on the isomerization of allyloxyalcohols catalyzed by $\left.\left[\mathrm{RuCl}_{2} \mathrm{PPh}_{3}\right)_{3}\right]$, described by us previously [21].

Surprisingly, the yield of $100 \%$ was noted within a short reaction time of $30 \mathrm{~min}$. However, the formed real catalyst was unstable (Run 12) and it was necessary to add a fresh portion of $\mathrm{Et}_{3} \mathrm{~N}$ to maintain a high catalyst activity in the next cycle (Run 13). Unfortunately, it became obvious that despite using fresh portions of $\mathrm{Et}_{3} \mathrm{~N}$, the catalyst did not retain its full efficiency in further recycling cycles and again, the prolongation of the reaction time was required to obtain practically maximal values of TON (Runs 14 and 15).

In general, we have found that the real catalyst formed in situ in the studied reaction system might be effectively reused at least fifteen times with a quantitative or very high conversion of the 
allyloxyalcohol substrate towards 1-propenyloxyalcohol product within a relatively short time (up to $2 \mathrm{~h}$ for Run 10 and Run 15). The obtained total turnover number value (TTN, cumulative TON values from all cycles) was as high as 14,964. Interestingly, the catalyst effectiveness remained high and constant up to the seventh run despite different, gradually decreased exothermal effects of reactions noted in each of these cycles after ca. 7-8 min of heating-in the first run with a fresh ruthenium complex the temperature reaction mixture reached the maximal value of $106^{\circ} \mathrm{C}$ after 6 min and only $84^{\circ} \mathrm{C}$ for the recycled catalyst during Run 7 . The slight increase of the reaction mixture temperature up to $85^{\circ} \mathrm{C}$ was again noted only for Run 11 , when a fresh portion of $\mathrm{Et}_{3} \mathrm{~N}$ was first added into the reaction system. This experimental result suggested again that the noted exotherm relates to the vigorous course of double bond migration reaction catalyzed by the hydride ruthenium catalyst.

Finally, it should be emphasized that presented results are substantially different than those obtained previously during the recycling of a ruthenium catalyst formed from $0.1 \mathrm{~mol} \%$ or $0.2 \mathrm{~mol} \%$ $\left[\mathrm{RuClH}(\mathrm{CO})\left(\mathrm{PPh}_{3}\right)_{3}\right]$ in the isomerization of alkyl allyl ethers at the higher reaction temperature of $120^{\circ} \mathrm{C}$ or $130{ }^{\circ} \mathrm{C}$, when the violent reaction with a high exothermal effect was observed only when using a fresh ruthenium complex (first cycle). Subsequent reuse of the formed catalyst contributed to a dramatic loss of its catalytic activity (second cycle) $[17,18]$. Therefore, because we have not observed any products of permanent catalyst coordination, it is probable that the ruthenium catalyst formed in situ in studied reaction was partially deactivated by traces of 1,4-bisallyloxybutane impurity present in the allyloxyalcohol substrate (similarly as by traces of water or 1,4-butanediol). On the other hand, our recycling outcomes are in a good correlation with the results of the recycling of the hydride ruthenium catalyst generated from $\left[\mathrm{RuCl}_{2}\left(\mathrm{PPh}_{3}\right)_{3}\right]$ and ethanol (used as a solvent) in the isomerization of the methyl chavicol or eugenol [43]. The authors did not observe any considerable changes in the conversion and selectivity of respective isomers up to fifth recycling cycles. However, the TON and TOF values were not reported, so it is difficult to assess the real efficiency of ruthenium catalyst. Considering the above results, it is reasonable to suggest that the hydroxyl group of the allyloxyalcohol substrate (functional primary alkyl alcohol) plays a key role in the formation (or reproduction) of the hydride (or dihydride) active species of the catalyst.

Generally, it is well known that the unavoidable changes in catalytic activity after each batch make any catalyst recycling scheme problematic in a controlled environment [4]. Additionally, in our experiments, the post distillation mixture containing catalyst was directly recycled without any purification. Therefore, it is not surprising that despite the apparently successful recycling results (15th runs with ca. $100 \%$ yield), the overall effectiveness of catalyst was relatively low $(\mathrm{TTN}=14,964)$. In the studied process the TTN was significantly lower than the TON of catalyst of ca. 100,000 reached in the first method, when the reaction was conducted at $80^{\circ} \mathrm{C}$ in the presence of $0.01 \mathrm{~mol} \%$ $\left[\mathrm{RuClH}(\mathrm{CO})\left(\mathrm{PPh}_{3}\right)_{3}\right]$ (entry 7 in Table 3), not to mention the extremely high catalyst effectivity with TON of 197,000 for $5 \mathrm{ppm}$ [Ru]at $120^{\circ} \mathrm{C}$ (entry 3 in Table 4). In light of the above, it seems that the further exploration of other, more expensive improved recycling strategies via the combination of the properties of homogeneous and heterogeneous catalysts is not reasonable from technological point of view, such as immobilization of homogeneous complex molecule or with using liquid-liquid multiphase systems $[5,8,42]$.

\section{Materials and Methods}

\subsection{Materials}

The 4-allyloxybutan-1-ol (purity > 99\%, impurities: traces of water ca. 700 ppm, 1,4-bisallyloxybutane ca. $0.3 \%$ or 1,4 -butanediol ca. $0.1 \%$ based on GC) was synthesized by our procedure of the allylation of a commercial 1,4-butanediol (Sigma-Aldrich, Poznań, Poland) with allyl chloride (Sigma-Aldrich) under the Phase Transfer Catalysis (PTC) conditions ( $50 \%$ aqueous solution $\mathrm{NaOH}, \mathrm{Bu}_{4} \mathrm{~N}^{+} \mathrm{HSO}_{4}^{-}$) and purified by vacuum distillation [22]. 
The presence and concentration of allyl hydroperoxides (AHP) generating in allyl substrate were measured semi-quantitatively in the range $0-0.5-2-5-10-25 \mathrm{mg} / \mathrm{L}\left(\mathrm{H}_{2} \mathrm{O}_{2}\right)$ by colorimetric method with using Quantofix ${ }^{\circledR}$ peroxides test strips (Merck, Poznań, Poland). The removing of AHP traces was conducted by using $\mathrm{PPh}_{3}$ in the weight ratio $\mathrm{PPh}_{3} /$ allyl substrate of 0.5 . The allyl substrate and a given amount $\mathrm{PPh}_{3}$ were placed into a round-bottom flask equipped with magnetic stirrer and stirred at room temperature under an air atmosphere until total reduction of AHP (usually up to ca. $30 \mathrm{~min}$ ). Next, the AHP-free allyl ether was purified by the vacuum distillation (bp. $62{ }^{\circ} \mathrm{C} / 0.5 \mathrm{mmHg}$ ) and kept in amber bottles under an argon atmosphere in refrigerated conditions without any reducing agent for prevention of auto-oxidation.

The ruthenium precursors: $\left[\mathrm{RuClH}(\mathrm{CO})\left(\mathrm{PPh}_{3}\right)_{3}\right],\left[\mathrm{RuH}_{2}(\mathrm{CO})\left(\mathrm{PPh}_{3}\right)_{3}\right],\left[\mathrm{RuCl}_{2}\left(\mathrm{PPh}_{3}\right)_{3}\right],\left[\mathrm{RuCl}_{2}\right.$ $\left.(\mathrm{CO})_{2}\left(\mathrm{PPh}_{3}\right)_{2}\right],\left\{\left[\mathrm{RuCl}_{2}(1,5-\mathrm{COD})\right]_{\mathrm{x}}\right\}$ and $\left\{\left[\mathrm{RuCl}_{2}(\mathrm{p}-\mathrm{Cym})\right]_{2}\right\}$ were purchased at Merck, Warszawa, Poland or Sigma-Aldrich. [ $\left.\mathrm{RuClH}(\mathrm{CO})\left(\mathrm{AsPh}_{3}\right)_{3}\right]$ were synthesized according to procedures known from the literature [44]. The amine $\mathrm{Bu}_{3} \mathrm{~N}$ obtained from commercial source (POCh, Gliwice, Poland) was dried (molecular sieves) and distilled before use.

\subsection{The Procedure of Isomerization Reaction}

Typically, all isomerization reactions were performed using the standard Schlenk's technique under the argon atmosphere and solvent-free conditions. The reaction was evaluated in terms of the allyl group conversion $(\alpha)$, the selectivity of the reaction to 1-propenyloxyalcohol $\left(S_{P}\right)$ and the reaction stereoselectivity was given as the percentage of $(E)$-1-propenyl group $(\% E)$ on the base of GC analysis (Trace Ultra GC, Thermo Scientific, with column Rtx-1, Restek, stationary phase: 100\% polydimethyl-polysiloxane, length: $30 \mathrm{~m}$, diameter: $0.53 \mathrm{~mm}$, thickness of the film: $1.5 \mu \mathrm{m}$, and the flame ionization detector, FID) or optionally GC-MS (Hewlett Packard 6890 gas chromatograph coupled to the HP 5973 Mass Selective Detector with the electron impact ionization) [21]. The spectroscopic data of the 1-propenyl ether derivatives as a mixture of the $E$ and $Z$ isomers were given in a previous publication [21].

Reactions were conducted with a magnetic stirrer in a small scale of $4 \mathrm{mmol}(520 \mathrm{mg})$ in a screw-capped ampoules or a larger scale of $50 \mathrm{mmol}(6.5 \mathrm{~g})$ or $150 \mathrm{mmol}(19.5 \mathrm{~g})$ of allyloxyalcohol in a round-bottom flask. The flask was sealed with a red rubber septum (Sigma-Aldrich).

In a small scale, the mixture of the allyl substrate containing $25 \mathrm{ppm}$ of the allyl hydroperoxides (AHP) $(4 \mathrm{mmol}, 520 \mathrm{mg}$ ) and the ruthenium pre-catalyst $(0.1 \mathrm{~mol} \%)$ was introduced in the screw-capped ampoules and heated in thermostated $\left( \pm 0.5^{\circ} \mathrm{C}\right)$ oil baths with magnetic stirrers under the argon atmosphere at the temperature of $80^{\circ} \mathrm{C}$ or $120^{\circ} \mathrm{C}$ for $0.5 \mathrm{~h}$ or $2 \mathrm{~h}$ (Table 1). The post-reaction mixtures were cooled down and analyzed.

On a larger scale, the reactants (allyl substrate containing 0 ppm or $25 \mathrm{ppm}$ of AHP, ruthenium complex, and optionally $\left.\mathrm{BuN}_{3}\right)$ were fed into the flask and heated in thermostated $\left( \pm 0.5^{\circ} \mathrm{C}\right)$ oil baths with magnetic stirrers under the argon atmosphere at given temperature and time (the reaction conditions: see footnotes of Tables and Figures in Results and Discussion section). The samples were taken at various times during the experiment using a glass syringe and were analyzed by GC. Optionally, continuous measurement of the reaction mixture temperature during the whole process was conducted by K-type thermocouple located in the reactor.

\subsection{The Procedure of Recycling Catalyst into the Isomerization Reaction}

The recycling of the ruthenium catalyst was carried out under the argon atmosphere and solvent-free and non-oxidative conditions via a procedure developed by us previously $[16,18]$. The AHP-free allyl substrate $(50 \mathrm{mmol}, 6.5 \mathrm{~g})$ and the ruthenium catalyst precursor $\left[\mathrm{RuClH}(\mathrm{CO})\left(\mathrm{PPh}_{3}\right)_{3}\right]$ $(0.1 \mathrm{~mol} \%, 47 \mathrm{mg})$ were placed into a round-bottom flask equipped with a red rubber septum and a K-type thermocouple and heated in thermostated $\left( \pm 0.5^{\circ} \mathrm{C}\right)$ oil baths with magnetic stirrers under the argon atmosphere at $80^{\circ} \mathrm{C}$ for $15 \mathrm{~min}$ to achieving of the quantitative yield of the 1-propenyl product. Then, the main product was distilled under the reduced pressure, usually $1 \mathrm{mmHg}$ at a temperature not 
exceeding $80^{\circ} \mathrm{C}$ (Run 1). After cooling, a new portion of the allyl substrate (and $\mathrm{Et}_{3} \mathrm{~N}$ in a molar ratio $\mathrm{Et}_{3} \mathrm{~N} /[\mathrm{Ru}]=10$, if necessary) was introduced directly into the reactor containing the ruthenium catalyst with ca. $2 \%$ of the distillation residue and a new catalytic reaction was started. These operations were repeated several times. The progress of reaction was monitored by GC. The isolated yields of the distilled product were in the range of $97-98 \%$. Additionally, changes in the temperature of the reaction mixture during heating were measured.

\section{Conclusions}

On the subject of homogeneous catalysis with soluble transition metal complexes (TMCs), basic research dominates, including new complexes new catalysts or new procedures. Undoubtedly, there are important studies focused directly on expanding fundamental knowledge about science and phenomena. On the other hand, a lot of the published work does not address the practical use of catalysts. The successful commercialization of selected TMCs-catalysed processes in sectors as diverse as bulk chemicals, specialty polymers, and pharmaceutical intermediates encourages further applied research and experimental development.

In this context, we have first presented the highly productive solvent-free synthesis of 4-(1-propenyloxy)butan-1-ol (as model hydroxyalkyl 1-propenyl ether) via the well established in the field of homogeneous catalysis the isomerization of allyl ether substrate catalyzed by the hydride ruthenium complexes. In our methodology, the almost quantitative reaction yields of 1-propenyl product were attained under moderate reaction conditions with using the extremely low loadings (5 ppm) of $\left[\mathrm{RuClH}(\mathrm{CO})\left(\mathrm{PPh}_{3}\right)_{3}\right]$ or $\left[\mathrm{RuCl}_{2}\left(\mathrm{PPh}_{3}\right)_{3}\right]$ as commercially available catalyst precursors. The addition of trace amounts of $\mathrm{Bu}_{3} \mathrm{~N}$ was essential for maintaining reaction chemoselectivity. At the temperature of $120^{\circ} \mathrm{C}$, the reactions occurred quickly during $0.5 \mathrm{~h}$ with the exothermal effect. The achieved, almost maximum, TON values of ca. $1.9 \times 10^{5}$ and high TOF of $3.9 \times 10^{5} \mathrm{~h}^{-1}$ are sufficient turnovers to be interesting for industrial use. Moreover, it should be pointed out that these excellent results were obtained for the allyl substrate with relatively high purity of $>99 \%$ (easily reached by vacuum distillation), but still containing impurities such as traces of 1,4-bisallyloxybutane 1,4-butanediol or water, identified as potential inhibitors of the ruthenium catalyst. The further, more thorough purification of the allyl substrate is possible, and it will certainly improve the efficiency of the catalyst, but simultaneously led to a substantial increase of the costs of the process, and for this reason, it will not be attractive to industry. On the other hand, the allyl hydroperoxides generated in the allyl substrate easily transformed the ruthenium catalysts into catalytically less active or inactive complexes, so they should be carefully removed via commonly known procedures used for solvent purifications or via the convenient and effective method used here with using commercial available very cheap triphenylphosphine.

Overall, the results described herein represent the first step to the development of practical and sustainable technology for industrially relevant UV-reactive difunctional 1-propenyl ether monomers containing a free hydroxyl group.

Funding: This research received no external funding.

Conflicts of Interest: The authors declare no conflict of interest.

\section{References}

1. Beller, M.; Blaser, H.-U. Organometallics as catalysts in the fine chemical industry. In Topics in Organometallic Chemistry; Springer: Berlin/Heidelberg, Germany, 2012.

2. Cornils, B.; Herrmann, W.A. Applied Homogeneous Catalysis with Organometallic Compounds, 2nd ed.; Wiley-VCH: Weinheim, Germany, 2002.

3. Sheldon, R.A.; Arends, I.W.C.E.; Hanefeld, U. Green Chemistry and Catalysis; Wiley-VCH: Weinheim, Germany, 2007. 
4. De Vries, J.G. Fine chemical synthesis-Homogeneous. In Encyclopedia of Catalysis; Horváth, I., Ed.; John Wiley \& Sons, Inc.: New York, NY, USA, 2002.

5. Hübner, S.; de Vries, J.G.; Farina, V. Why does industry not use immobilized transition metal complexes as catalysts? Adv. Synth. Catal. 2016, 358, 3-25. [CrossRef]

6. Larsen, C.R.; Grotjahn, D.B. The value and application of transition metal catalyzed alkene isomerization in industry. In Applied Homogeneous Catalysis with Organometallic Compounds: A Comprehensive Handbook in Four Volumes, 3rd ed.; Cornils, B., Herrmann, W.A., Beller, M., Paciello, R., Eds.; Wiley-VCH: Weinheim, Germany, 2018.

7. Kuznik, N.; Krompiec, S. Transition metal complexes as catalysts of double-bond migration in O-allyl systems. Coord. Chem. Rev. 2007, 251, 222-233. [CrossRef]

8. Behr, A.; Neubert, P. Applied Homogeneous Catalysis; Wiley-VCH: Weinheim, Germany, 2012.

9. van der Drift, R.C.; Sprengers, J.W.; Bouwman, E.; Mul, W.P.; Kooijman, H.; Spek, A.L.; Drent, E. Ruthenium-catalyzed isomerization of allylic alcohols: Oxidation state determines resistance against diene inhibition. Eur. J. Inorg. Chem. 2002, 2147-2155. [CrossRef]

10. Hassam, M.; Taher, A.; Arnott, G.E.; Green, I.R.; van Otterlo, W.A.L. Isomerization of allylbenzenes. Chem. Rev. 2015, 115, 5462-5569. [CrossRef]

11. Akutagawa, S. Enantioselective isomerization of allylamine to enamine: Practical asymmetric synthesis of (-)-menthol by Rh-BINAP catalysts. Top. Catal. 1997, 4, 271-274. [CrossRef]

12. Schmidt, B. An olefin metathesis/double bond isomerization sequence catalyzed by an in situ generated ruthenium hydride species. Eur. J. Org. Chem. 2003, 5, 816-819. [CrossRef]

13. Nelson, S.; Kan, W. Asymmetric claisen rearrangements enabled by catalytic asymmetric Di(allyl) ether synthesis. J. Am. Chem. Soc. 2006, 128, 4232-4233. [CrossRef]

14. Greene, T.W.; Wuts, P.G.M. Protective Groups in Organic Synthesis, 3rd ed.; John Wiley \& Sons, Inc.: Hoboken, NJ, USA, 1999; pp. 67-74.

15. Crivello, J.; Rajaraman, S. Transition metal-catalyzed tandem isomerization and cationic polymerization of allyl ethers. I. Discovery and scope. J. Polym. Sci. A Polym. Chem. 1997, 35, 1593-1604. [CrossRef]

16. Krompiec, S.; Kuźnik, N.; Urbala, M.; Rzepa, J. Isomerization of alkyl allyl and allyl silyl ethers catalyzed by ruthenium complexes. J. Mol. Catal. A Chem. 2006, 248, 198-209. [CrossRef]

17. Urbala, M. The effectiveness of ruthenium(II) complexes and ruthenium trichloride as pre-catalysts in solvent-free isomerization of model alkyl allyl ether. Appl. Catal. A Gen. 2010, 377, 27-34. [CrossRef]

18. Urbala, M. Solvent-free [Ru]-catalyzed isomerization of allyl glycidyl ether: The scope, effectiveness and recycling of catalysts, and exothermal effect. Appl. Catal. A Gen. 2015, 505, 382-393. [CrossRef]

19. Krompiec, S.; Antoszczyszyn, M.; Urbala, M.; Bieg, T. Isomerization of allyl ethers of diols and triols catalyzed by ruthenium complexes. Pol. J. Chem. 2000, 74, 737-739. [CrossRef]

20. Urbala, M.; Kuźnik, N.; Krompiec, S.; Rzepa, J. Highly selective isomerization of allyloxyalcohols to cyclic acetals or 1-propenyloxyalcohols. Synlett 2004, 7, 1203-1206. [CrossRef]

21. Urbala, M.; Krompiec, S.; Penkala, M.; Danikiewicz, W.; Grela, M. Solvent-free Ru-catalyzed isomerization of allyloxyalcohols: Methods for highly selective synthesis of 1-propenyloxyalcohols. Appl. Catal. A Gen. 2013, 451, 101-111. [CrossRef]

22. Antoszczyszyn, M.; Janus, E.; Urbala, M. Synthesis of mono- and diallyl ethers of 1,4-dihydroxybutane, Z-1,4-dihydroxy-2-butene and 1,4-dihydroxy-2-butyne. Pol. J. Appl. Chem. 1999, 43, 77-83.

23. Martysz, D.; Urbala, M.; Antoszczyszyn, M.; Pilawka, R. 1-Propenyl ethers of butanediol as effective modifiers of UV-cured epoxy coatings in cationic polymerization. Polimery 2002, 11-12, 849-851. [CrossRef]

24. Martysz, D.; Antoszczyszyn, M.; Urbala, M.; Krompiec, S.; Fabrycy, E. Synthesis of 1-propenyl ethers and their using as modifiers of UV-cured coatings in radical and cationic polymerization. Prog. Org. Coat. 2003, 46, 302-311. [CrossRef]

25. Czech, Z.; Urbala, M. UV-crosslinked acrylic pressure-sensitive adhesive systems containing unsaturated ethers. Polimery 2007, 6, 438-442. [CrossRef]

26. Sangermano, M.; Razza, N.; Crivello, J.V. Cationic UV-curing: Technology and applications. Macromol. Mater. Eng. 2014, 299, 775-793. [CrossRef]

27. Goethals, E.J.; Trossaert, G.G.; Hartmann, P.J.; Engelen, K. Branched polymers by cationic ring-opening polymerization. Macromol. Chem. Macromol. Symp. 1993, 73, 77-89. [CrossRef] 
28. Kubisa, P. Hyperbranched polyethers by ring-opening polymerization: Contribution of activated monomer mechanism. J. Polym. Sci. A Polym. Chem. 2003, 41, 457-468. [CrossRef]

29. Kim, W.G.; Ahn, H.K.; Lee, H.W.; Kim, S.H.; Crivello, J.V. Synthesis and photopolymerization of propenyl ether and epoxy functionalized siloxanes. Opt. Mater. 2003, 21, 343-347. [CrossRef]

30. Li, S.J.; He, Y.; Nie, J. Photopolymerization of hybrid monomer 3-(1-propenyl)oxypropyl acrylate. J. Photochem. Photobiol. A Chem. 2007, 191, 25-31. [CrossRef]

31. Moszner, N.; Lamparth, I.; Angermann, J.; Fischer, U.K.; Zeuner, F.; Bock, T.; Liska, R.; Rheinberger, V. Synthesis of bis(3-\{[2-(allyloxy)ethoxy]methyl\}-2,4,6-trimethylbenzoyl)(phenyl)phosphine oxide-A tailor-made photoinitiator for dental adhesives. Beilstein J. Org. Chem. 2010, 6. [CrossRef]

32. Ota, K.; Kai, K.; Uchida, H. Preparation of Polyalkylene glycol 1-alkenyl Ethers. Japan Patent JP2000143567 A 20000523, 23 May 2000.

33. Bäckvall, J.-E. Transition metal hydrides as active intermediates in hydrogen transfer reactions. J. Organomet. Chem. 2002, 652, 105-111. [CrossRef]

34. Yue, C.J.; Liu, Y.; He, R. Olefins isomerization by hydride-complexes of ruthenium. J. Mol. Catal. A Chem. 2006, 259, 17-23. [CrossRef]

35. Krompiec, S.; Penkala, M.; Szczubiałka, K.; Kowalska, E. Transition metal compounds and complexes as catalysts in synthesis of acetals and orthoesters: Theoretical, mechanistic and practical aspects. Coord. Chem. Rev. 2012, 56, 2057-2095. [CrossRef]

36. Schildknecht, C.E. Allyl Compounds and Their Polymers (Including Polyolefins); Wiley-Interscience: New York, NY, USA, 1973.

37. van Leeuwen, P.W.N.M.; Chadwick, J.C. Homogeneous Catalysts. Activity-Stability-Deactivation; Wiley-VCH: Weinheim, Germany, 2011.

38. Lyons, J.E. Effect of hydroperoxide on the isomerization of olefins catalysed by a ruthenium(II) complex. J. Chem. Soc. D 1971, 562-563. [CrossRef]

39. Toivonen, H. Autoxidation of allyl ether compounds. Part 1. Reactivity of allyl ether alcohols. Acta Chemica Scandinavica B 1984, 38, 37-42. [CrossRef]

40. Bingham, D.; Webster, D.E.; Wells, P.B. Homogeneous catalysis of olefin isomerisation. Part V. Pent-1-ene isomerisation catalysed by solutions of $\mathrm{RuHCl}(\mathrm{PPh} 3) 3$ and of $\mathrm{RuHCl}(\mathrm{CO})(\mathrm{PPh} 3) 3$; variation of the isomeric composition of pent-2-ene and its attribution to steric factors. J. Chem. Soc. Dalton Trans. 1974, 1519-1521. [CrossRef]

41. Taskinen, E. Relative thermodynamic stabilities of isomeric alkyl allyl and alkyl (Z)-propenyl ethers. Tetrahedron 1993, 49, 11389-11394. [CrossRef]

42. Cole-Hamilton, D.J.; Tooze, R.P. Catalyst Separation, Recovery and Recycling: Chemistry and Process Design; Springer: Dordrecht, The Netherlands, 2006. [CrossRef]

43. Sharma, S.K.; Srivastava, V.K.; Jasra, R.V. Selective double bond isomerization of allyl phenyl ethers catalyzed by ruthenium metal complexes. J. Mol. Catal. A Chem. 2006, 245, 200-209. [CrossRef]

44. Sánchez-Delgrado, R.A.; Lee, W.; Choi, S.R.; Cho, Y.; Jun, M.J. The chemistry and catalytic properties of ruthenium and osmium complexes. Part 5 . Synthesis of new compounds arsine ligands and catalytic activity in the homogeneous hydrogenation of aldehydes. Trans. Met. Chem. 1991, 16, 241-244. [CrossRef]

Publisher's Note: MDPI stays neutral with regard to jurisdictional claims in published maps and institutional affiliations.

(C) 2020 by the author. Licensee MDPI, Basel, Switzerland. This article is an open access article distributed under the terms and conditions of the Creative Commons Attribution (CC BY) license (http://creativecommons.org/licenses/by/4.0/). 